\title{
Gemeinsamer Beitrag zum Gelingen
}

\section{„101 Gründe, die Pflegeschule am Wilhelminenspital zu besuchen“}

Trotz stürmischem Schneefall herrschte keine Spur von vorweihnachtlicher Ruhe Ende November vergangenen Jahres anlässlich des Tages der offenen Tür an der Schule für allgemeine Gesundheits- und Krankenpflege am Wilhelminenspital. Das Schulteam freute sich über das rege Interesse von mehr als 200 Gästen, darunter auch Generaloberin Charlotte Staudinger vom Wiener Krankenanstaltenverbund und Ursula Frohner, Präsidentin des Österreichischen Gesundheits- und Krankenpflegeverbandes.

Der Tag stand unter dem bereits wohlbekannten Motto: „101 Gründe, die Pflegeschule am Wilhelminenspital zu besuchen“. Viele Schülerinnen und Schüler unserer Schule haben aktiv zum Gelingen dieses Tages beigetragen und konnten den Interessenten vermitteln, dass die Gründe zum Schulbesuch im Wilhelminenspital vor allem in der Art der Ausbildung und im Klima an unserer Schule zu finden sind.

Die Interessenten konnten verschiedene Stationen besuchen. Schülerinnen und Schüler brachten den Gästen die Tätigkeitsbereiche der Pflege praktisch und theoretisch näher. So bestand die Möglichkeit, selbst einen Verbandwechsel durchzuführen oder eine Pflegedokumentation einzu-
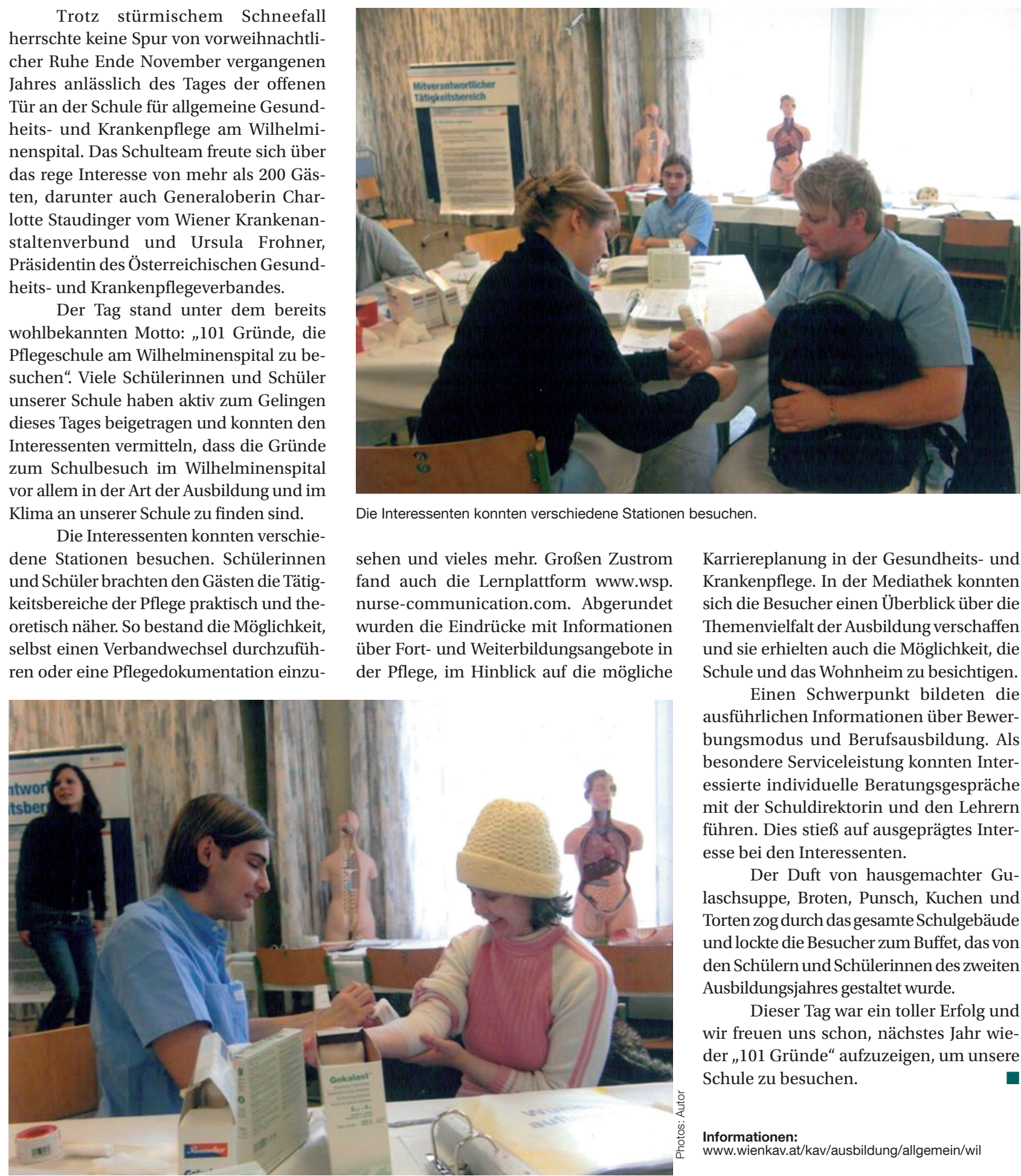

Die Interessenten konnten verschiedene Stationen besuchen. sehen und vieles mehr. Großen Zustrom fand auch die Lernplattform www.wsp. nurse-communication.com. Abgerundet wurden die Eindrücke mit Informationen über Fort- und Weiterbildungsangebote in der Pflege, im Hinblick auf die mögliche
Die Schüler brachten ihren Gästen die Tätigkeitsbereiche der Pflege praktisch und theoretisch näher.
Karriereplanung in der Gesundheits- und Krankenpflege. In der Mediathek konnten sich die Besucher einen Überblick über die Themenvielfalt der Ausbildung verschaffen und sie erhielten auch die Möglichkeit, die Schule und das Wohnheim zu besichtigen.

Einen Schwerpunkt bildeten die ausführlichen Informationen über Bewerbungsmodus und Berufsausbildung. Als besondere Serviceleistung konnten Interessierte individuelle Beratungsgespräche mit der Schuldirektorin und den Lehrern führen. Dies stieß auf ausgeprägtes Interesse bei den Interessenten.

Der Duft von hausgemachter Gulaschsuppe, Broten, Punsch, Kuchen und Torten zog durch das gesamte Schulgebäude und lockte die Besucher zum Buffet, das von den Schülern und Schülerinnen des zweiten Ausbildungsjahres gestaltet wurde.

Dieser Tag war ein toller Erfolg und wir freuen uns schon, nächstes Jahr wieder „101 Gründe“ aufzuzeigen, um unsere Schule zu besuchen.

Informationen:

www.wienkav.at/kav/ausbildung/allgemein/wi 